\title{
Chemical Studies on Blasticidin S
}

\section{Part II. The Structure of Cytosinine and Uracinine}

\author{
By Noboru $\bar{O}_{\mathrm{Take}}$, Setsuo Takeuchi, Toyoshige Endō and Hiroshi Yonehara \\ Institute of Applied Microbiology, The University of Tokyo, Tokyo \\ Received August 18, 1965
}

Acid hydrolysis of cytosinine gave each one mole of cytosine, levulinic acid, ammonia and carbon dioxide. Reduction of cytosinine with $\mathrm{PtO}_{2}$ afforded a mixture of dihydrocytosinine, 3-amino-tetrahydropyran-2-carboxylic acid and cytosine. Ozonolysis of $\mathbf{N}, \mathrm{N}^{\prime}$. diacetylcytosinine methyl ester, followed by oxidation with hydrogen peroxide and acid hydrolysis gave erythro-D- $\beta$-hydroxyaspartic acid. These data permitted the assignment of structure (I) for cytosinine. Acid hydrolysis of uracinine gave uracil instead of cytosine, therefore, the structure (II) could be assigned to uracinine. Some stereochemical features and mechanism of levulinic acid formation were discussed.

The isolation of cytosinine and uracinine from the hydrolysate of blasticidin $S^{1 /}$ and their characterization were described in the previous paper. ${ }^{2}$, We have presented the structure of cytosinine and blasticidin S (III) in recent communications, ${ }^{3,4}$ in which the nucleoside was demonstrated that it is consisted of cytosine and a peculiar sugar of 2,3unsaturated 4-amino-4-deoxyuronic acid structure. Such a nucleoside is quite unique one which arises from natural source.

This paper concerns with the chemical evidences which permitted the assignment of structure I and II for cytosinine and uracinine respectively.

Cytosinine (I), $\mathrm{C}_{10} \mathrm{H}_{12} \mathrm{O}_{4} \mathrm{~N}_{4}$, m.p. $244 \sim 245^{\circ} \mathrm{C}$ (dec.), $[\alpha]_{D}^{18}-20^{\circ} \mathrm{C}$ (c, 1 in $\mathrm{H}_{2} \mathrm{O}$ ) was an amphoteric compound of $\mathrm{pKa} 2.4,4.6$ and 8.0. Van Slyke determination proved the presence of two free amino groups. By the action of methanol containing $3 \%$ hydrogen chloride,

1) S. Takeuchi, H. Hirayama, K. Ueda, H. Sakai and H. Yonehara, J. Antibiotics, Ser. A, 11, 1 (1958).

2) H. Yonehara, S. Takeuchi, N. Otake, T. Endō, Y. Sakagami and Y. Sumiki, ibid., 16, 195 (1963).

3) N. Otake, S. Takeuchi, T. Endō and H. Yonehara, Tetrahedron Letters, 1965, 1405.

4) N. Ötake, S. Takeuchi, T. Enđō and H. Yonehara, ibid., 1965, 1411.<smiles>Nc1ccn(C2C=CC(N)C(C(=O)O)O2)c(=O)n1</smiles><smiles>NC1C=CC(n2ccc(O)nc2=O)OC1C(=O)O</smiles>

(II)<smiles>CN(CCC(N)CC(=O)NC1C=CC(n2ccc(N)nc2=O)OC1C(=O)O)C(=N)N</smiles>

: III :

I gave corresponding methyl ester dihydrochloride, $\mathrm{C}_{10} \mathrm{H}_{11} \mathrm{O}_{3} \mathrm{~N}_{4} \cdot\left(\mathrm{OCH}_{3}\right) \cdot 2 \mathrm{HCl}$ (IV), m.p. $220 \sim 223^{\circ} \mathrm{C}$ (dec.), pKa 4.6 and 8.0 , therefore, the presence of one free carboxylic function was demonstrated. UV spectra of I showed $\lambda_{\max }$ $274 \mathrm{~m} \mu(\varepsilon 13,800)$ in $0.1 \mathrm{~N}$ hydrochloric acid which shifted to $\lambda_{\max } 267 \mathrm{~m} \mu(\varepsilon 7,500)$ in $0.1 \mathrm{~N}$ sodium hydroxide. This data indicated probable presence of cytosine (V), on which a 


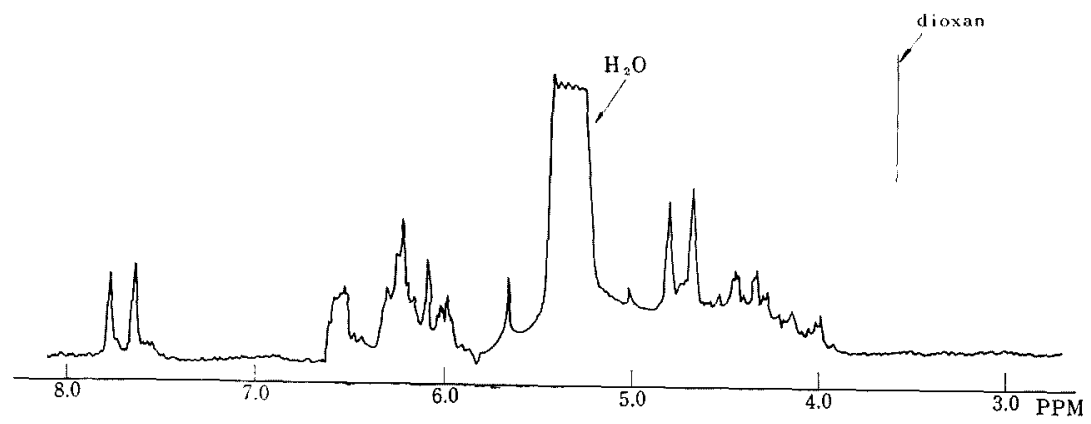

FIG. 1. NMR Spectrum of Sodium Cytosininate in $\mathrm{D}_{2} \mathrm{O}$.

substituent attached at $\mathrm{N}$-I position.

The NMR spectra (in $\mathrm{D}_{2} \mathrm{O}$ ) supported this assumption as shown in Fig. 1, two protons appeared as doublet of $A B$ type $(J=7.5$ c.p.s.) at 7.72 and 6.14 p.p.m. which could be assigned to the typical signals of protons at $\mathrm{C}_{6}$ and $\mathrm{C}_{5}$ of cytosine nucleus ${ }^{5}$ respectively. Furthermore, the presence, of two ethylenic protons appeared at $6.45 \sim 6.00$ p.p.m. as multiplet provided informative data for the elucidation of unknown portion.

Acid hydrolysis of I gave each one mole of $\mathrm{V}$, levulinic acid, ammonia and carbon dioxide as characterizable products, ${ }^{2}$ whereas further attempt to cleave the linkage of I into $Y$ and its substitutent was unsuccessful without extensive decomposition. It was very reasonable to presume the presence of sugar in I by the levulinic acid formation.

In an effort to gain information regarding the sugar portion, reduction and oxidative cleavage of ethylenic linkage were next undertaken. On reduction with platinum oxide catalyst in acetic acid, I afforded a mixture of dihydrocytosinine (VI), $\mathrm{C}_{10} \mathrm{H}_{14} \mathrm{O}_{4} \mathrm{~N}_{4} \cdot \mathrm{HCl}$, m.p. $230 \sim 233^{\circ} \mathrm{C}$ (dec.), a hydrogenolysis product (VII), $\mathrm{C}_{6} \mathrm{H}_{11} \mathrm{O}_{3} \mathrm{~N}, \mathrm{~m} . \mathrm{p} .275 \sim 278^{\circ} \mathrm{C}$ and $\mathrm{V}$ The facile hydrogenolysis of $\mathrm{I}$ to VII and $\mathrm{V}$ indicated that an ethylenic function in $\mathrm{C}_{6}$ moiety located at allylic position to the glycosidic C-N bond.

5) J.P. Kokko, J. H. Goldstein and L. Mandel, J. Am. Chem. Soc., 83, 2909 (1963).<smiles>Nc1ccn(C2C=CC(N)C(C(=O)O)OC2c2ccccc2)c(=O)n1</smiles>

VII characterized as monoamino monocarboxylic compound of pKa 2.4 and 9.2, gave corresponding $\mathrm{N}$-acetyl methyl ester, $\mathrm{C}_{6} \mathrm{H}_{9} \mathrm{O}_{2} \mathrm{~N}$. $\left(\mathrm{OCH}_{3}\right) \cdot\left(\mathrm{CH}_{3} \mathrm{CO}\right), \mathrm{m} . \mathrm{p} .130^{\circ} \mathrm{C}$. The IR spectrum of VII and deuterated VII exhibiting characteristic bands of tetrahydropyran ${ }^{61}$ at 1100 and $1060 \mathrm{~cm}^{-1}$ (C-O-C stretching vibration) indicated the presence of tetrahydropyran ring rather than tetrahydrofuran." The NMR spectrum of VII in $\mathrm{D}_{2} \mathrm{O}$ (p.p.m.) was most instructive, showing $\mathrm{C}_{2}$ proton doublet at 3.80 ( $\mathrm{J}=10.5$ c.p.s.), $\mathrm{C}_{3}$ proton in broad at $4.20, \mathrm{C}_{4}, \mathrm{C}_{5}$ methylene protons as multiplet at $1.70 \sim 2.20$ and $\mathrm{C}_{6}$ methylene protons as broad at 3.40 p.p.m. The NMR spectral evidence permitted the elucidation of VII as 3-aminotetrahydropyran-2-carboxylic acid.

The result of oxidative cleavage of ethylenic group in $C_{6}$ moiety provided unequivocal 6) S. C. Barket and R.M. Badger, J. Chem. Soc., 1950,
4397.
7) S. A. Barker and R. Stephens. ibid., 1954, 4550. 


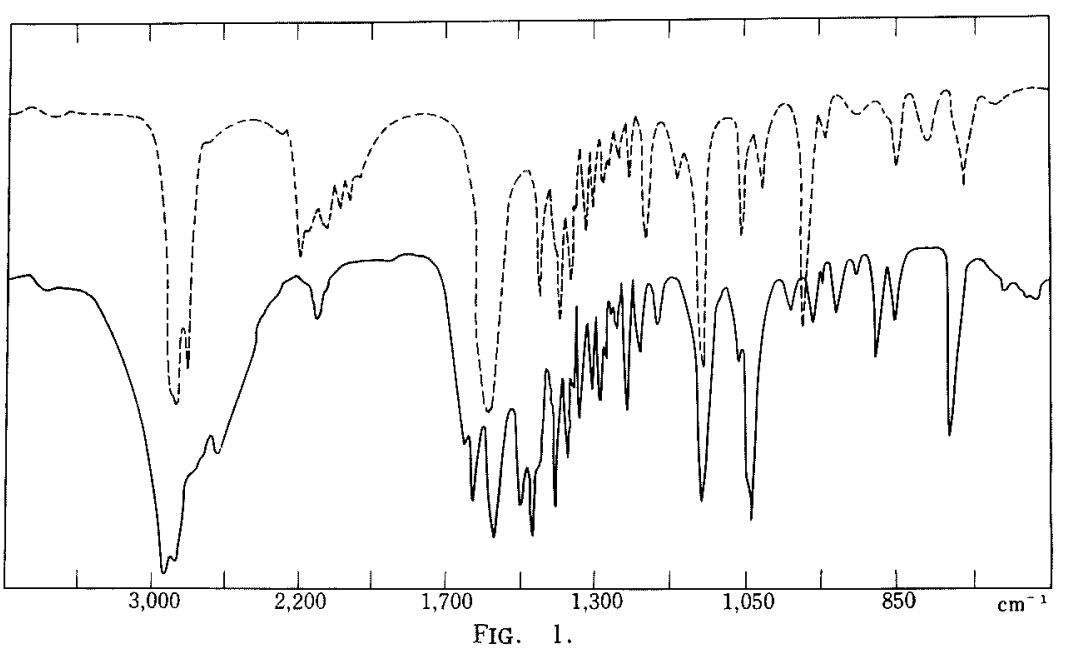

FIG. 2. Infrared Spectrum of 3-Aminotetrahydropyran-2-Carboxylic Acid (VII).

-- deuterio (VII)

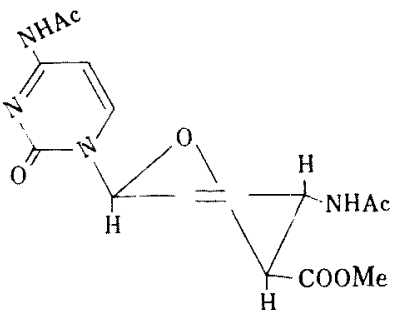

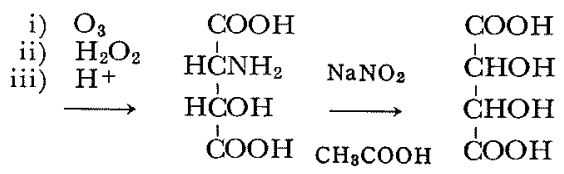

(IX) meso-tartaric acid evidence for structure VII, and consequently for the complete structure of I. IV was acetylated with acetic acid and triethylamine in methanol to afford $\mathrm{N}, \mathrm{N}^{\prime}$-diacetylcytosinine methyl ester (VIII), $\mathrm{C}_{10} \mathrm{H}_{9} \mathrm{O}_{3} \mathrm{~N}_{4} \cdot\left(\mathrm{OCH}_{3}\right)$. $\left(\mathrm{CH}_{3} \mathrm{CO}\right)_{2}$, m.p. $263 \sim 266^{\circ} \mathrm{G}$ (dec.) as crystalline needles. Ozonolysis of VIII in acetic acid followed by oxidation with hydrogen peroxide and acid hydrolysis furnished $\beta$-hydroxyaspartic acid (IX), $\mathrm{C}_{4} \mathrm{H}_{7} \mathrm{O}_{5} \mathrm{~N}$, m.p. $286 \sim 288^{\circ} \mathrm{C}$ (dec.), $[\alpha]_{\mathrm{D}}^{20}-47^{\circ} \mathrm{C}$ (c, 1 in $\left.\mathrm{H}_{2} \mathrm{O}\right)$. Diazotization of IX gave meso-tartaric acid indicating the erythro-D-configuration ${ }^{8}$ of the amino acid. IX was a substantially important structural fragment of the sugar proton in I and was also obtained from the parent antibotic itself by the ozonolysis.

The mechanism of levulinic acid formation is necessary to be considered. Transformation of hexoses through the intermediate (X) into levulinic acid by the action of acids was well established. $^{91}$ It seems probable that proto-

8) H. J. Salbach, J. Biol. Chem., 229, 437 (1957)

9) H. P. Teunissen, Rec. Trav. Chem., 50, 1 (1930). 


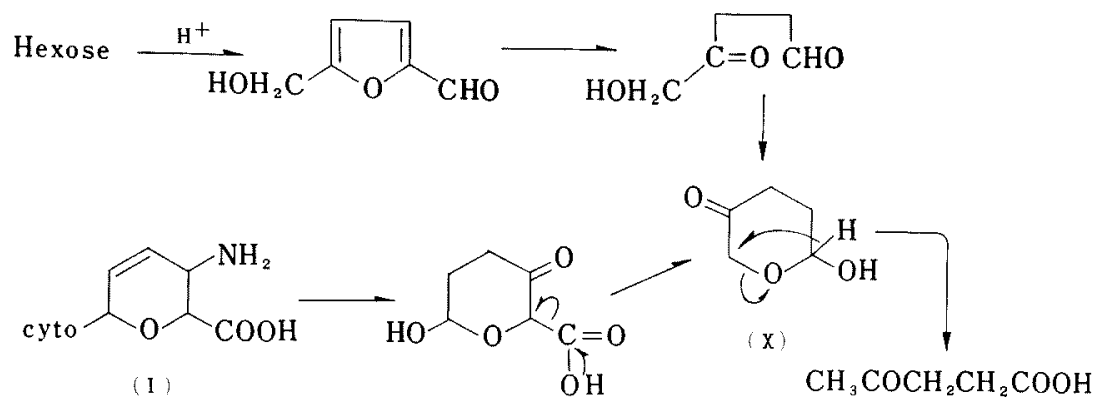

tropic rearrangement of double bond coupled with the deamination and decarboxylation gave $\mathrm{X}$, which was further degradated to levulinic acid.

Formation of formic acid in the hydrolysate of III by alkali was reported as structural fragment in the previous paper, ${ }^{2)}$ but according as the progress of our investigation, formic acid was demonstrated as an extensive decomposition product of I. Indeed, prolonged refluxing of I with $3 \mathrm{~N}$ sodium hydroxide, gave one mole of formic acid almost quantitatively. One of the possible route of this reaction is presumed as follows; alkaline hydrolysis of I Five rise to a compourd XI which affords an intermediate enal system XII, and the nucleo-
(S)-configuration at $\mathrm{C}_{4}^{\prime}$ and $\mathrm{C}_{5}^{\prime}$ respectively and, moreover, the NMR spectrum of VI which exhibited a distinct doublet of $\mathrm{C}_{5}^{\prime}$ proton at 3.65 p.p.m. ( $\mathrm{J}=10.5$ c.p.s. $)$ demonstrated the $\mathrm{C}_{4}^{\prime}-\mathrm{C}_{5}^{\prime}$ protons to be diaxial. Conclusively, the $\mathrm{D}$-configuration of aminohexeuronic acid moiety was established. ${ }^{101}$ The configuration of glycosidic linkage was determined as $\beta .^{11}$

Uracinine $^{11}$ was obtained by the alkaline hydrolysis of I. ${ }^{21}$ Acid hydrolysis of II gave uracil instead of cytosine, levulinic acid, ammonia and carbon dioxide. ${ }^{2}$ Hydrogenation of II gave VII indicated that II differed from $\mathrm{I}$ at aglycone portion and the $\mathrm{C}_{6}$ moiety remained intact, consequently structure II was assigned for uracinine.

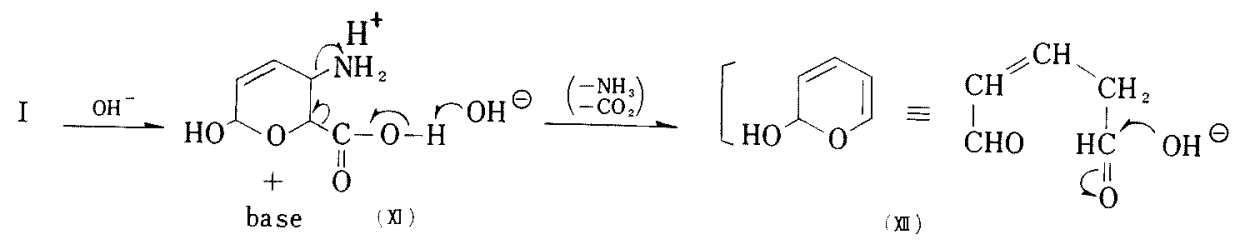

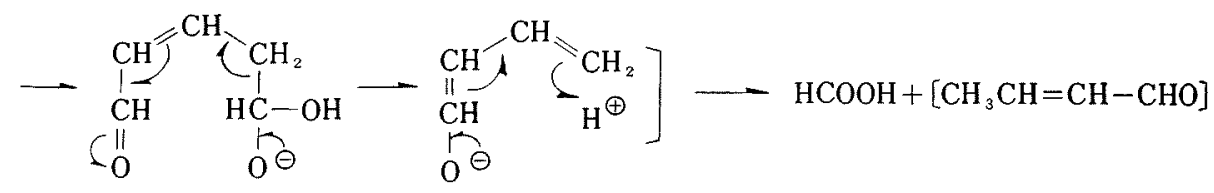

phylic attack of $\mathrm{OH}^{-}$to XII may release formic acid.

Finally, stereochemical feature of I was considered, e.g. the configuration of erythro$D$ - $\beta$-hydroxy aspartic acid obtained as structural fragment of I provided evidence for the

\section{EXPERIMENTAL}

Melting points were taken with a Kofler block and were not corrected. Infrared spectra were measured in

10) In the previous paper, ${ }^{3}$ ) we have misassigned the configuration of erythro-p- $\beta$-hydroxyaspartic acid and led to the erroneous conclusion of $(R)$-configuration at $C_{4}^{\prime}$ and $C_{5}{ }^{\prime}$,

11) The details will be published. 
nujol mull with Koken DS 301 spectrophotometer and ultraviolet spectra with Cary 11 spectrophotometer. NMR spectra of 60 megacycle were measured with Varian A-60 or JNM-C-60 spectrometers.

\section{Dissociation constant}

Potentiometric titration was carried out by the procedure described by Parke and Davis.12) About $10 \mathrm{mg}$ of the sampte was dissolved in $2 \mathrm{ml}$ of $0.1 \mathrm{~N}$ hydrochloric acid and titrated with $1 \mathrm{~N}$ sodium hydroxicte using microsyringe with the calibration of $0.002 \mathrm{ml}$. During the titration the mixture was constantly stirred by microstirrer and the surface of the solution was covered with gentle current of nitrogen. $\mathrm{pH}$ was measured using $\mathrm{pH}$ meter model HM-5 (Toa Dempa Kogyo Co. Ltd.)

\section{Cytosinine (I)}

The sample of I was prepared by the procedures in the previous paper. ${ }^{2}$ After recrystallization from hot water I gave fine needles of m.p. $244 \sim 245^{\circ} \mathrm{C}$ (dec.), $[\alpha]_{D}^{18}-20^{\circ} \mathrm{C}$ (c, 1 in $\mathrm{H}_{2} \mathrm{O}$ ), $\lambda_{\operatorname{mux}} 274 \mathrm{~m} \mu$ $(\varepsilon 13,800)$ in $0.1 \mathrm{~N}$ hydrochloric acid, $\lambda_{\max } 267 \mathrm{~m} \mu$ $(\varepsilon 7,500)$ in $0.1 \mathrm{~N}$ sodium hydroxide. Anal. Found: C, $47.51 ; \mathrm{H}, 4.92 ; \mathrm{N}, 21.63$. Calcd. for $\mathrm{C}_{10} \mathrm{H}_{12} \mathrm{O}_{4} \mathrm{~N}_{4}$ : $\mathrm{C}, 47.62 ; \mathrm{H}, 4.80 ; \mathrm{N}, 22.22$.

\section{Cytosinine methyl ester dihydrochloride (IV)}

I ( $3 \mathrm{~g})$ was suspended in dry methanol ( $15 \mathrm{ml}$ ) containing $3 \%$ hydrogen chloride and the mixture was refluxed gently for one hour. After cooling a crystalline precipitate deposited $(2.8 \mathrm{~g})$. Recrystallization from hot methanol gave fine needles of m.p. $220 \sim 223^{\circ} \mathrm{C}$ (dec.). Potentiometric titration showed two titrable functions as base of pKa 4.6 and 8.0. The NMR spectrum exhibited characteristic singlet of $-\mathrm{COOCH}_{3}$ at 3.57 p.p.m. Anal. Found: C, 39.08; H, $4.50 ; \mathrm{N}, 16.38 ; \mathrm{Cl}, 20.83$. Calcd. for $\mathrm{C}_{11} \mathrm{H}_{16} \mathrm{O}_{4} \mathrm{~N}_{4} \mathrm{Cl}_{2}$ : C, 38.95; H, 4.75; N, 16.52; Cl, 20.91 .

\section{Hydrogenation of $I$}

I $(2.2 \mathrm{~g})$ was hydrogenated over platinum oxide catalyst $(500 \mathrm{mg})$ in acetic acid until hydrogen uptake had ceased. About 1.5 mole of hydrogen was absorbed. After filtration of the catalyst, the filtrate was evaporated in vacuo with addition of water. The residue was separated by partition chromatography on cellulose powder using solvent system of $n$-butanol-acetic acid-water $(2: 1: 1)$ to afford three compounds in pure form.

The first compound has been eluated at earlier fractions, m.p. over $300^{\circ} \mathrm{C}$, which was identified with 12) T.V. Parke and W.W. Davis, Anal. Chem., 26, 642 (1954). cytosine by the comparison of infrared spectrum.

Next was a hydrogenolysis product (VII), being distributed in the fractions of no UV absorption but ninhydrin positive, obtained as crystalline precipitate (800 mg). Recrystallization from aqueous ethanol gave needles, 'm.p. $275 \sim 278^{\circ} \mathrm{C}, \mathrm{pKa} 2.4$ and 9.2. $\nu_{\max } 3200$ (shoulder), 2750, 2640, 1610 (COO-), 1105 and $1048(\mathrm{C}-\mathrm{O}-\mathrm{C}) \mathrm{cm}^{-1}$. Anal. Found: C, 49.50; H, 7.25; N, 9.56. Calcd. for $\mathrm{C}_{6} \mathrm{H}_{11} \mathrm{O}_{3} \mathrm{~N}: \mathrm{C}, 49.64 ; \mathrm{H}$, $7.64 ;$ N. 9.65 .

The third compound was distributed in the last fractions showing UV absorption and ninhydrin reaction. After removal of the solvent, resulting syrup showed no tendency to crystallize. Trituration of the syrup with ethanol $(20 \mathrm{ml})$ containing concentrated hydrochloric acid $(2 \mathrm{ml})$ afforded a crystalline needles $(980 \mathrm{mg})$. Recrystallization from $80 \%$ ethanol gave fine needles of m.p. $230 \sim 233^{\circ} \mathrm{C}$ (dec.) of VI $\lambda_{\max } 274 \mathrm{~m} \mu(\varepsilon 12,000)$ in $0.1 \mathrm{~N} \mathrm{HCl}, \lambda_{\max } 267 \mathrm{~m} \mu$ $(\varepsilon 7,000)$ in $0.1 \mathrm{~N} \mathrm{NaOH}$. Anal. Found: $\mathrm{C}, 41.14 ; \mathrm{H}$, $5.51 ; \mathrm{N}, 19.15 ; \mathrm{Cl}, 12.37$. Calcd. for $\mathrm{C}_{10} \mathrm{H}_{14} \mathrm{O}_{4} \mathrm{~N}_{4}$. HCl: C, 41.31; H, 5.20; N, 19.27; Cl. 12.15 .

\section{N-Acetyl methyl ester of VII}

VII $(500 \mathrm{mg}$ ) was acetylated with acetic anhydride and triethylamine in methanol and the mixture was stood over night at room temperature. After removal of the solvent in vacuo, a residual syrup was dissolved in $15 \mathrm{ml}$ of methanol and slight excess of diazomethane saturated in ether solution $(10 \mathrm{ml})$ was added. After three hours, the solvent was removed in vacuo, and the residue crystallized as needles. Recrystallization from ethyl acetate-ligroin gave fine needles of m.p. $130 \sim 130.5^{\circ} \mathrm{C} . \nu_{\max } 3390,1740,1670$, 1230, 1130 and $1047 \mathrm{~cm}^{-1}$. Anal. Found: C, 53.65; $\mathrm{H}, 7.30 ; \mathrm{N}, 6.82$. Calcd. for $\mathrm{C}_{9} \mathrm{H}_{15} \mathrm{O}_{4} \mathrm{~N}: \mathrm{C}, 53.72$; $\mathrm{H}, 7.51 ; \mathrm{N}, 6.96$.

\section{$\mathrm{N}, \mathrm{N}^{\prime}$-diacetyl cytosinine methyl ester (VIII)}

To a mixture of IV (2.5 g) in dry methanol $(30 \mathrm{ml})$ cooled in ice water, triethylamine $(3 \mathrm{ml})$ and acetic anhydride $(5 \mathrm{ml})$ was added dropwise and the solution stood overnight. The mixture was carefully evaporated in vacuo with addition of water twice, d crystalline solid deposited. Recrystallization from hot water gave VIII as needles, m.p. $263 \sim 266^{\circ} \mathrm{C}$ (dec.) $\nu_{\max } 1740,1650,1600,1100$ and $1050 \mathrm{~cm}^{-1}$. Anal. Found: C, 51.38; H, 5.31; N, 15.89. Calcd. for $\mathrm{C}_{15} \mathrm{H}_{18} \mathrm{O}_{5} \mathrm{~N}_{4}: \mathrm{C}, 51.42 ; \mathrm{H}, 5.18 ; \mathrm{N}, 15.99$.

\section{Erythro-D- $\beta$-hydroxyaspartic acid (IX)}

A mixture of VIII $(2.5 \mathrm{~g})$ in acetic acid $(100 \mathrm{ml})$ was ozonolysed for three hours at room temperature. 
Acetic acid was carefully evaporated in vacuo and resulted ozonide was treated with hydrogen peroxide $(30 \%, 5 \mathrm{ml})$ at room temperature overnight. Subsequently $3 \mathrm{~N}$ hydrochloric acid $(15 \mathrm{ml})$ was added to the reaction mixture and the solution was refluxed three hours under the current of nitrogen. The hydrolysate was continuously extracted with ether, the ether extracts gave a yellow oil. Digestion of this with chloroform afforded oxalic acid $(520 \mathrm{mg})$. The aqueous layer was dried up in vacuo and the residual solids were chromatographed on cellulose powder using $n$-butanol-acetic acid-water $(5: 1: 4)$. The marked ninhydrin positive fractions were collected and evaporated in vacuo to afford almost pure crystals $(350 \mathrm{mg})$. Recrystallization from $50 \%$ aquous ethanol gave crystalline rods of m.p. $287 \sim 288^{\circ} \mathrm{C}$ (dec.), $[\alpha]_{\mathrm{D}}^{20}-47^{\circ}$ (c, 1 in $\mathrm{H}_{2} \mathrm{O}$ ). The infrared spectrum of this compound coincided completely with that of authentic $\beta$-hydroxyaspartic acid.

From the cellulose column, it has been eluted some unreacted cytosine, ammonium chloride and an intractable oil in the preceding fractions of IX.

\section{meso-Tartaric acid from IX}

To the aqueous solution of IX (60 $\mathrm{mg}$ in $5 \mathrm{ml} \mathrm{H}_{2} \mathrm{O}$ ), acetic acid $(3 \mathrm{ml})$ and sodium nitrate $(30 \mathrm{mg})$ were added, the mixture was kept $5^{\circ} \mathrm{C}$ with stirring for two hours. The solution was evaporated in vacuo at $40^{\circ} \mathrm{C}$ with addition of water to remove excess of acetic acid and finally the residue was made up to $10 \mathrm{ml}$. Calcium chloride $(40 \mathrm{mg})$ was added to this solution and insoluble crystals of calcium mesotartarate $(40 \mathrm{mg})$ deposited immediately. The identity was confirmed by comparison of infrared spectrum.

Uracinine (II)

II was obtained by the procedures described pre- viously ${ }^{2}$ and was recrystallized from hot water. m.p. $286 \sim 289^{\circ} \mathrm{C}$ (dec.) $[\alpha]_{\mathrm{p}}^{13}-28.87^{\circ}$ (c, 2 in $0.1 \mathrm{~N}$ $\mathrm{HCl}$ ). pKa 2.4, 8.0 and 9.8. Anal. Found: C, 47.25; $\mathrm{H}, 4.31 ; \mathrm{N}, 16.61$. Calcd. for $\mathrm{C}_{10} \mathrm{H}_{11} \mathrm{O}_{5} \mathrm{~N}_{3}: \mathrm{C}, 47.43$; $\mathrm{H}, 4.38 ; \mathrm{N}, 16.60$.

\section{Hydrogenation of uracinine (II)}

II $(1.0 \mathrm{~g})$ in acetic acid $(20 \mathrm{ml})$ was hydrogenated over $\mathrm{PtO}_{2}$ until the hydrogen up take had ceased, the filtrate was evaporated in vacuo and residual syrup was chromatographed on cellulose powder using $n$-butanol-acetic acid-water $(2: 1: 1)$. The fractions showed ninhydrin positive and lack of UV absorption were collected and evaporated in vacuo to afford crystalline needles $(250 \mathrm{mg})$, which was identified with VII by infrared spectrum. The fractions has been eluted afterward of VII showed ultraviolet absorption peak at $267 \mathrm{~m} \mu$ and also ninhydrin positive, presumably corresponded to dihydrouracinine, were not further characterized.

Acknowledgement. The authors wish to express their hearty thanks to Emeritus Professor $Y$. Sumiki for his encouragement through the work. They are also grateful to Kaken Chemical Co. Ltd. for supply the sample of blasticidin S and to Dr. S. Morita of Central Research Laboratories, Mitsubishi Chemical Industries Ltd. and to Drs. G. Sunagawa and I. Iwai of Central Research Laboratories, Sankyo Co. for NMR measurement. This work was supported in party by the U.S. Public Health Service Research Grant CA05082-05 from The National Cancer Institute. 